\title{
Relaciones texto-imagen en el libro álbum
}

\author{
Magglio Chiuminatto Orrego $\left(^{*}\right)$
}

"Así pues, ¿quieres oír una historia?

Bueno, hace tiempo sabía un montón de historias interesantes. Algunas eran tan divertidas que te desmayarías de risa, y otras tan espantosas que no querrías volver

a oírlas jamás.

Pero me he olvidado ya de todas".

Tan, S. La cosa perdida. Bárbara Fiore Editora. Jerez de la Frontera, España, 2007.

\begin{abstract}
RESUMEN
El artículo trata las "Relaciones texto-imagen en el libro álbum", objeto literario y artístico que presenta una oportunidad especialmente fructífera para analizar las relaciones entre la comunicación escrita y la comunicación visual, y constituye, además, un recurso de gran relevancia dentro de las tareas de fomento a la lectura que impulsan instituciones como los jardines infantiles, las escuelas y las bibliotecas públicas.

En las relaciones texto-imagen la delimitación preliminar de ambos conceptos resulta necesaria toda vez que la escritura puede ser considerada también como una categoría de imagen. Debido a esto, optamos por considerar ambos términos a partir de la definición de W. Mitchell, quien plantea hablar de la Familia de Imágenes más que de la Imagen como concepto único. A partir de esta perspectiva, utilizamos como herramienta de análisis para las relaciones entre texto (imágenes verbales) e imagen (imágenes gráficas), la taxonomía establecida por Radan Martinec y Andrew Salway en su artículo "Un sistema para las relaciones texto-imagen en los nuevos (y
\end{abstract}

(*) Doctor en Filosofía y Letras de la Universidad Autónoma de Barcelona. Académico de la Pontificia Universidad Católica de Valparaíso y de la Universidad Tecnológica Metropolitana. Gestor Cultural de la Biblioteca Regional Metropolitana.

Artículo recibido el 18 de enero de 2011. Aceptado por el Comité Editorial el 11 de abril de 2011.

Correo electrónico: chiuminatto@gmail.com 
antiguos) medios de comunicación" desarrollada a partir de una combinación de los planteamientos de Roland Barthes y la gramática funcional de Michael Halliday.

$\mathrm{Al}$ aplicar esta red conceptual al análisis de las relaciones texto-imagen en el libro ilustrado y particularmente a algunos fragmentos de la obra del autor australiano Shaun Tan, podemos observar planos de significación, tensiones y procesos de lectura superpuestos, que constituyen la riqueza expresiva del formato y que permiten abordar de manera más clara y sistemática sus capacidades para incentivar la lectura y para desarrollar procesos creativos de transmisión de contenidos.

$$
\begin{gathered}
\text { Palabras clave: } \\
\text { Álbum - imagen - texto - lectura - libro. }
\end{gathered}
$$

\begin{abstract}
The article is about the relationship between image and text in illustrated books. This artistic and literary object offers an especially fruitful opportunity to analyze the relationship between the written communication and the visual communication, and it also constitutes a resource of great relevance to institutions that introduce reading such as kindergartens, schools and public libraries.

In the image-text relationship, the preliminary limitation of both concepts makes necessary because the written can also be considered as well as an image a category. In this sense, we considered both terms from the definition of W. Mitchell, who prefers to talk about a Family of Images rather than about Image as a unique concept. From this perspective, we use as an analysis tool for the relationships between text (as verbal images) and images (as graphic images) the taxonomy established by Radan Martinec and Andrew Salway in their article "A system for image-text relations in new (and old) means of comunication" which was developed from a combination of approaches by Roland Barthes and the functional grammar of Michael Halliday.

When this network of concepts is applied to the analysis of the relationship between text and image in the illustrated book, and specially to some fragments of the work of the Australian author Shaun Tan, we can observe several degrees of meaning, tensions and processes of reading overlap, which constituted the expressive richness of format and wich allows us to study, in a more clear and systematic way, the capacity to encourage reading and to develop creative processes of content transfer.
\end{abstract}

Key words:

Illustration - image - text - reading - book. 


\section{Introducción}

Abordaremos las relaciones texto-imagen en el libro álbum ya que el formato de este objeto literario y artístico, como intentaremos mostrar, presenta una oportunidad especialmente fructífera para analizar las relaciones entre la comunicación escrita y la comunicación visual, y constituye, además, un recurso de gran relevancia dentro de las tareas de fomento a la lectura que impulsan instituciones como los jardines infantiles, las escuelas y, lógicamente, las bibliotecas públicas. El libro álbum constituye, entonces, además de un caso de análisis particular sobre la continuidad entre la lectura textual y la lectura visual en un mismo soporte, una herramienta potente y extendida de animación a la lectura.

Sin embargo, una de las primeras interrogantes que este objeto de investigación genera es justamente el problema de la flexibilidad de los límites entre los conceptos de texto e imagen, ya que la noción de imagen es sumamente amplia y se encuentra en las bases mismas de la filosofía, epistemología, psicología, y la propia lingüística, por ejemplo, cuando Saussure (Saussure,1988) aborda el concepto de imagen acústica y señala que "los hechos de conciencia, que llamaremos conceptos, se encuentran asociados a las representaciones de los signos lingüísticos o imágenes acústicas que sirven a su expresión" (comprendidos como elementos mentales analíticamente separables del fenómeno específico de la fonación y la audición, por ser un proceso exclusivamente mental).

¿Cómo podemos limitar el concepto de imagen para observar sus posibles relaciones con un texto que también es referido por uno de los padres de la lingüística como imagen? Esta diferencia que a veces parece tan clara entre el verbo y la imagen y que, como tal, identificó incluso conflictos religiosos en la sociedad occidental durante los siglos VIII y IX -entre los iconoclastas que querían purificar la iglesia y los partidarios de la liturgia tradicional-, se hace más compleja, menos nítida, dentro de la teoría social. A partir de esta problemática, W. Mitchell desarrolla un análisis muy interesante en su artículo “QQué es una imagen?" (Mitchell, 1984), y plantea la transversalidad del concepto a través de distintos campos de conocimiento y, por lo tanto, de diversas disciplinas.

Más que de 'La Imagen', Mitchell plantea hablar de la Familia de Imágenes, en la que se consideran imágenes gráficas (como pinturas, esculturas, diseños); imágenes ópticas (como las generadas por los espejos, reflejos y proyecciones de diverso tipo, entre las cuales podríamos considerar hasta cierto punto las generadas por la tecnología, que se fundamentan en procesos ópticos); imágenes perceptuales (las producidas por los sentidos, la manera en que captamos la apariencia de las cosas); las imágenes mentales (que, en principio, constituyen un grupo particular, generadas por así decirlo, de manera privada, dentro de nuestros cerebros, como los sueños, las memorias, y las ideas); y las imágenes verbales (que consideran tanto al lenguaje figurado, las metáforas, como las simples descripciones, el hecho gráfico de la escritura o incluso las proposiciones: como señala Wittgenstein "una proposición es un cuadro de realidad (...) un modelo de la realidad como nosotros lo imaginamos"). 
Dentro de esta familia, ni las imágenes gráficas, ni las ópticas, ni siquiera las perceptuales pueden ser investidas de una condición de estabilidad, de transparencia o de universalidad mayor que los otros tipos. Al respecto la antropología está llena de ejemplos y podemos recurrir aquí al caso del antropólogo que, a raíz de su experiencia en proyectos de desarrollo, narra la situación de un grupo de funcionarios que intenta explicar a una comunidad indígena la importancia de combatir una determinada plaga, como podría ser la mosca de fruta, para lo cual utilizan la proyección de una diapositiva con la imagen del insecto. Al salir, todos los asistentes locales comentan que los funcionarios son unos embusteros, unos mentirosos, que los quieren convencer de fantasías, pues en ese lugar jamás ha existido un insecto de ese tamaño. Cualquier imagen es culturalmente construida.

Justamente porque la más enigmática de todas las categorías de imagen, la imagen mental, es el espacio donde se construyen todas las otras imágenes. Por lo tanto, una palabra, una imagen verbal, comparte el mismo espacio de representación y construcción que una imagen gráfica, óptica o perceptual y su distinción queda concentrada en el nivel de abstracción o de sustituciones que se requieren para ir de la percepción, a la construcción del pictograma, ideograma o signo fonético. Nuevamente Wittgenstein, citado por Mitchell, señala que "las imágenes mentales de los colores, formas, sonidos, etc., que juegan un rol en la comunicación por los significados del lenguaje, nosotros las ponemos en la misma categoría de los colores realmente vistos, de los sonidos verdaderamente escuchados". En la misma categoría en cuanto son fenómenos internos de la mente humana.

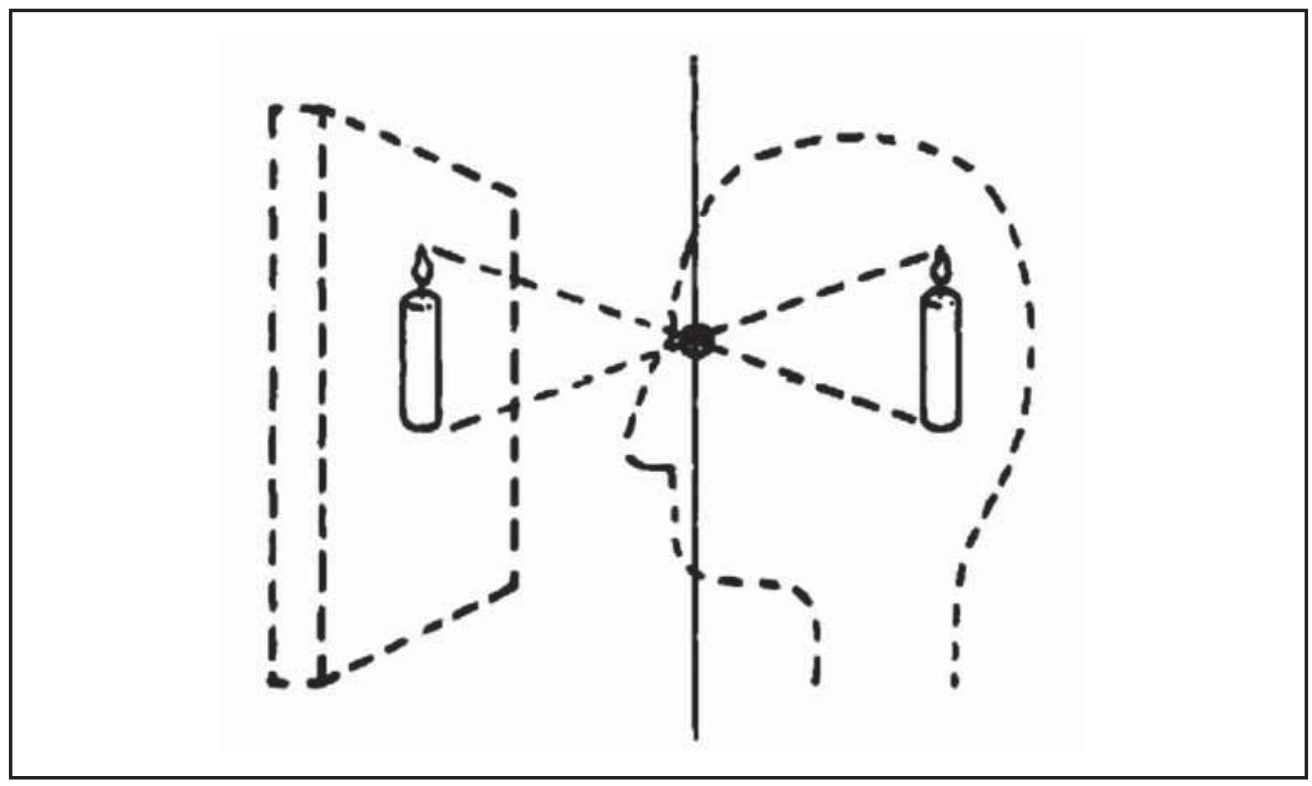

En Mitchell, W. J. T. “What Is an Image?”. New Literary History, Vol. 15 (Nº 3), Spring, 1984, pp. $503-537$. 


\section{Modelo de análisis de las relaciones texto-imagen}

En el caso de las relaciones texto-imagen, entonces, de lo que hablamos es de relaciones entre parientes, cuyo ancestro común podríamos decir que es la imagen mental. Radan Martinec y Andrew Salway en su artículo "Un sistema para las relaciones texto-imagen en los nuevos (y antiguos) medios de comunicación" desarrollan un mecanismo de análisis basado en la proyección de los planteamientos de Roland Barthes sobre la gramática funcional de Michael Halliday, el cual resulta apropiado para aproximarse a las relaciones que deseamos investigar aquí entre texto e imagen en el libro álbum.

Barthes identifica tres posibles relaciones entre texto e imagen las que, muy sencillamente, se definen como Ilustración (en que la imagen dilucida o aclara un texto); Anclaje (en que por el contrario, es el texto el que aclara o dilucida la imagen); y Relevo (en que estos dos elementos se encontrarían en un mismo nivel).

El comentario crítico de un cuadro, por ejemplo, sería un ejemplo típico de ilustración, pues necesita de la imagen de la obra para adquirir sentido. En cuanto al anclaje, Barthes usa como ejemplo una publicidad que presenta algunas frutas diseminadas alrededor de una escalera y el texto que dice "Como si usted hubiese recorrido el huerto", lo cual aleja otras interpretaciones posibles (como desorden) y la orienta en cambio hacia un significado agradable. Por otra parte, las relaciones de relevo serían más características del cine, donde los diálogos y la filmación de las situaciones estarían en niveles paralelos.

Para Martinec y Salway, esta clasificación de Barthes es similar y puede vincularse con el sistema establecido por Michael Halliday para las relaciones entre frases (o proposiciones) dentro de un conjunto o complejo de frases. En primer lugar, de acuerdo con su estatus o categoría, las relaciones entre las cláusulas (o para el caso que nos ocupa, la relaciones entre texto e imagen) pueden ser de igualdad o desigualdad. Cuando la relación es de igualdad, Halliday sólo consideró la posibilidad de que ambos elementos fueran independientes, pero de acuerdo con la noción de relevo de Barthes, Martinec y Salway incorporan también la posibilidad de que ambas sean complementarias. En cuanto a las relaciones de desigualdad, se entiende que el texto y la imagen están en una relación de estatus diferente cuando uno de ellos modifica al otro, en tal caso, el elemento modificador es considerado dependiente del elemento modificado.

Por otra parte, desde un punto de vista lógico-semántico, las relaciones entre texto e imagen pueden ser de expansión o de proyección. La expansión se puede dar a través de elaboración (elaboration), cuando uno de los elementos da una descripción más detallada del otro; extensión (extension) cuando uno de los elementos entrega información adicional o complementaria de lo que ya se ha dicho; y amplificación o realce (derivados del término inglés enhancement, que también se podría traducir como mejora) cuando el texto o la imagen se califican uno a otro en términos circunstanciales de razón, propósito, tiempo. Halliday señala que la relación de expansión podría ser comparada con lo que sucede en un edificio: elaborar sería mejorar los espacios 
de la estructura existentes, extender es construir nuevas habitaciones o rehacer las existentes y amplificación o realce es mejorar el entorno de este edificio (los parques, las plazas, la iluminación adyacente).

Finalmente, los procesos de proyección considerados por Halliday se refieren a mecanismos de cita o reproducción que se pueden establecer entre la imagen y el texto, o viceversa. Estos mecanismos de cita pueden tratarse de citas textuales o directas de la locución (palabras), como sucede en los globos o bocadillos del cómic, o reproducir fundamentalmente los significados, es decir, las ideas, lo cual también se codifica, por ejemplo, en los diagramas de flujo y otras representaciones gráficas de datos y procesos o utilizando burbujas en los bocadillos del cómic.

Si bien el planteamiento de Martinec y Salway resulta muy sugestivo para el análisis de las relaciones entre texto e imagen (como campo de exploración, que necesita ser desarrollado con mayor profundidad), su aplicación a casos concretos por los mismos autores no resulta sencilla y no logran, a nuestro juicio, emplear el modelo con claridad en los ejemplos que analizan. No obstante, esta red conceptual podría elaborarse con mayor precisión y constituye un intento interesante por lograr una sistematización de las informaciones relativas a las relaciones texto imagen.

\section{La obra de Shaun Tan y la riqueza expresiva del libro álbum}

Utilizaré de forma más o menos flexible, y no exhaustiva, algunos de los aspectos lógico-semánticos del modelo para referirme a procesos de relación entre texto e imagen que se producen en el libro álbum, comprendido éste de acuerdo con lo señalado por Laura Guerrero, (Guadarrama, 2005), como un subgénero complejo de la literatura infantil y juvenil, que puede ser narrativo o poético y que es un arte mixto en que se combina el texto escrito y la ilustración de manera fusionada. En la actualidad, el libro-álbum ha incorporado técnicas de lenguaje cinematográfico, de programas de computación y de la publicidad, entre otros.

Básicamente, nos referiremos a las relaciones de expansión que se pueden dar entre el texto y la imagen dentro de este soporte. Es curioso, en este sentido, detectar cómo el libro álbum puede explicitar y poner en evidencia los mecanismos internos del lenguaje, la construcción de significados, los procesos de lectura, con un carácter lúdico, que juega con los recursos de la expansión y proyección que se pueden producir entre el texto y la imagen. 


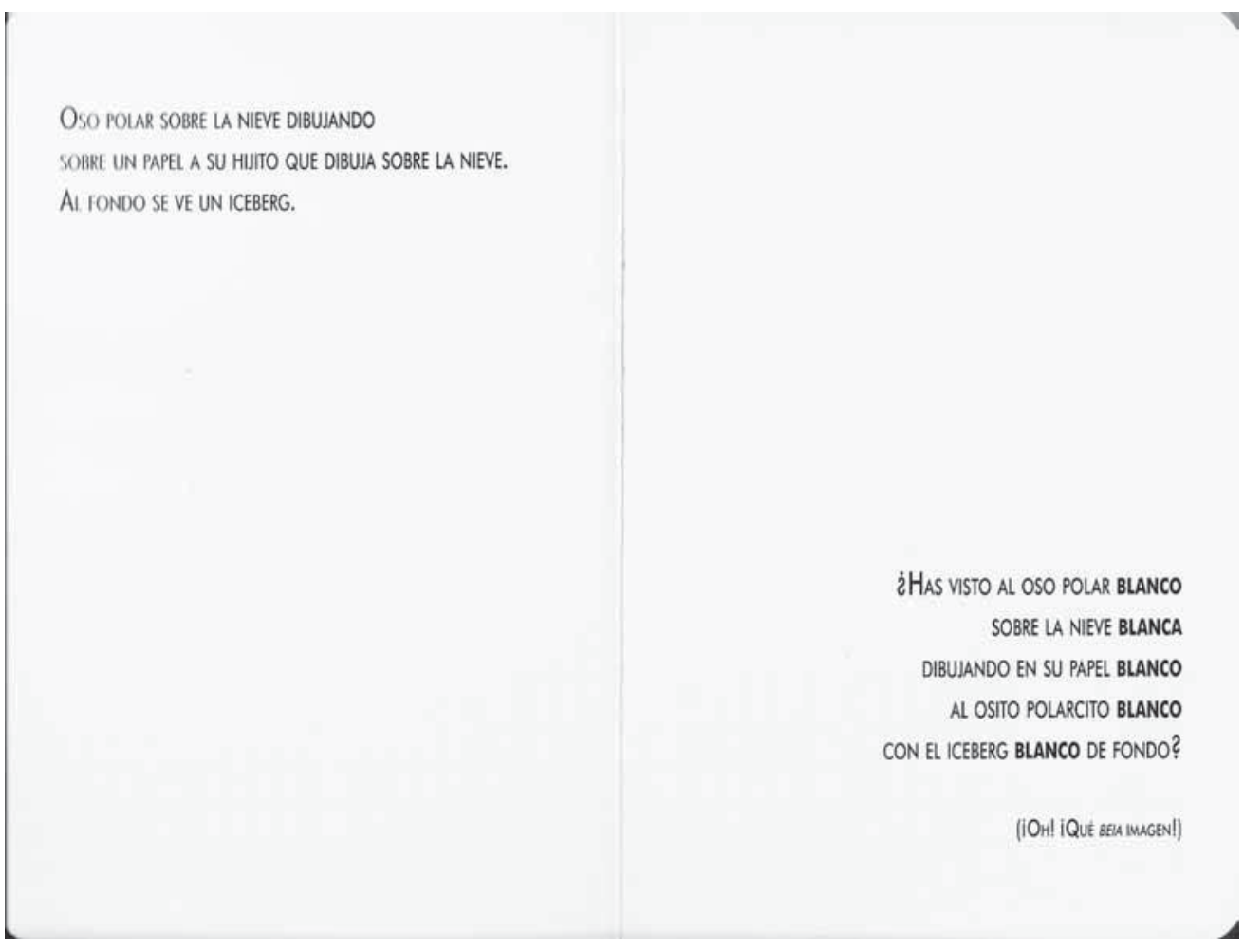

Istvanch. ¿Has visto? Ediciones del Eclipse. Buenos Aires, 2006.

En el libro de Istvansch, llamado ¿Has visto?, se explicita sobre una superficie blanca (y en realidad hace lo mismo con distintos colores) la magia de la elaboración a través de la suma de estratos, en que el texto pone al lector (ya sea un niño o un adulto) frente a los procesos de construcción mental o cultural de la imagen, al punto que ésta puede surgir (por así decirlo) de la nada. "Oso polar sobre la nieve dibujando sobre un papel a su hijito que dibuja sobre la nieve, al fondo se ve un iceberg. ¿Has visto el oso polar blanco, sobre la nieve blanca, dibujando en su papel blanco, al osito polarcito blanco, con el iceberg blanco al fondo?"

Evelyn Arispe, en su artículo "El libro ilustrado para niños y la crítica", señala: "en estos libros infantiles ilustrados hay elementos posmodernos: narraciones fragmentadas, intertextualidad, elementos metafictivos (elementos en la narración que llaman la atención sobre la construcción de ésta), la presencia de símbolos e ironía y límites indefinidos entre géneros, estilos y entre realidades objetivas y percepciones subjetivas".

De acuerdo con Perry Nodelman, citado justamente por Arispe, "los libros ilustrados más exitosos parecen ser aquellos en que la 'unidad en un nivel más alto' emerge de ilustraciones y textos que son notoriamente fragmentarios -cuya diferencia mutua 
(o discordancia) es una parte significativa del efecto y significado del conjunto". La tensión también se genera, por otra parte, entre la inercia lineal de la lectura y la contemplación (más lenta) de la mirada frente a la imagen, de forma que el lector duda entre estos dos impulsos al abordar el libro ilustrado.

Tomaremos, como caso representativo del libro álbum, la obra de Shaun Tan, ilustrador australiano, que ha recibido un amplio reconocimiento de la crítica por el conjunto de su obra y que refleja con mucha riqueza la versatilidad y complejidad de los libros ilustrados.

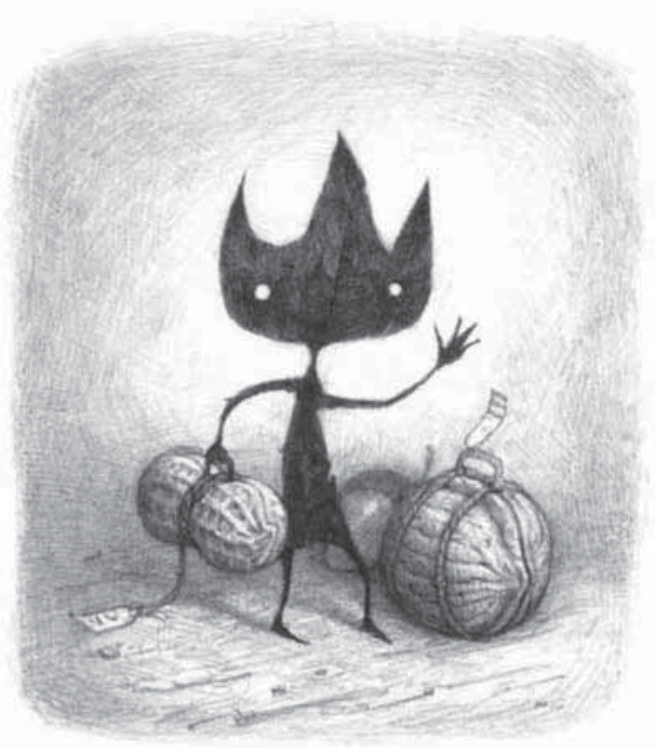

Hace unos años tuvimos a un estudiante extranjero de intercambio viviendo

con nosotros. A todos nos costaba mucho pronunciar su nombre correctamente, pero a él no le importaba. Nos dijo que le llamáramos simplemente "Eriç.

Tan, S. Cuentos de la periferia. Bárbara Fiore Editora. Jerez de la Frontera, España, 2008, p. 8.

En el libro, Cuentos de la periferia se encuentra la historia de Eric. En esta imagen, de acuerdo con el modelo de Martinec y Salway, existe una relación de expansión por ampliación o realce, en la que el texto nos entrega una serie de antecedentes adicionales sobre el contexto de la imagen. El texto, por sí solo, resulta bastante prosaico, normal: "Hace unos años tuvimos un estudiante extranjero de intercambio viviendo con nosotros. A todos nos costaba mucho pronunciar su nombre correctamente, pero a él 
no le importaba. Nos dijo que lo llamáramos simplemente 'Eric' ".

Sin embargo, la imagen gráfica ironiza el sentido que se podría construir a través de la imagen verbal. Configura lo que Jonathan Potter en su libro “La representación de la realidad" denomina un discurso ironizante, en cuanto pone en jaque la transparencia, la factualidad y la factibilidad de la situación descrita. Nos sitúa, como diría Foucault (2004), en la evidencia fantástica del correlato, nos lleva a aceptar sus reglas particulares, que no coinciden con las leyes de la vida cotidiana, sino con las que el proceso mismo de enunciación va creando en complicidad con el lector.

$\mathrm{Y}$, sin embargo, no eran el tipo de preguntas que yo esperaba.
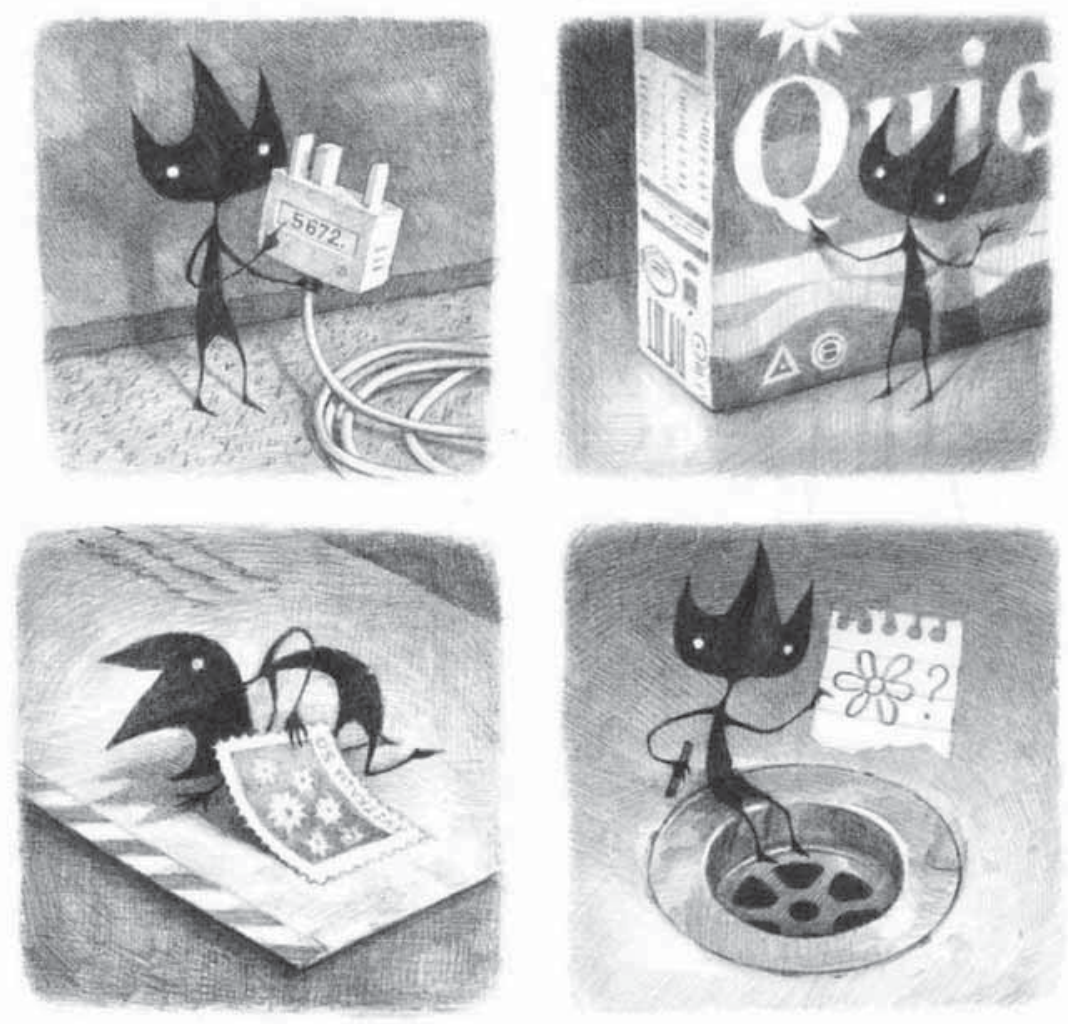

\footnotetext{
La mayoria de las veces sólo podia responder: «No estoy muy segura»
}

o «Asi son las cosas». No me sentia precisamente muy útil.

Tan, S. Cuentos de la periferia. Bárbara Fiore Editora. Jerez de la Frontera, España, 2008. p. 11. 
En algunos casos, la imagen puede elaborar el contenido del texto, como en esta lámina, en la que vemos que a través de la imagen gráfica se ejemplifica el tipo de preguntas que Eric, el estudiante de intercambio, puede plantear. " $Y$, sin embargo, no eran el tipo de preguntas que yo esperaba. La mayoría de las veces sólo podía responder: 'No estoy muy segura' o 'Así son las cosas'. No me sentía precisamente muy útil".

Justamente, porque estas preguntas de Eric se refieren a la utilización de los signos en nuestra cultura, con lo cual el personaje plantea un cuestionamiento sobre los sistemas de significación y la arbitrariedad de su funcionamiento. En una reflexión sobre particularidades culturales que también se dirige hacia el diseño, los objetos y los envoltorios, entre otros.
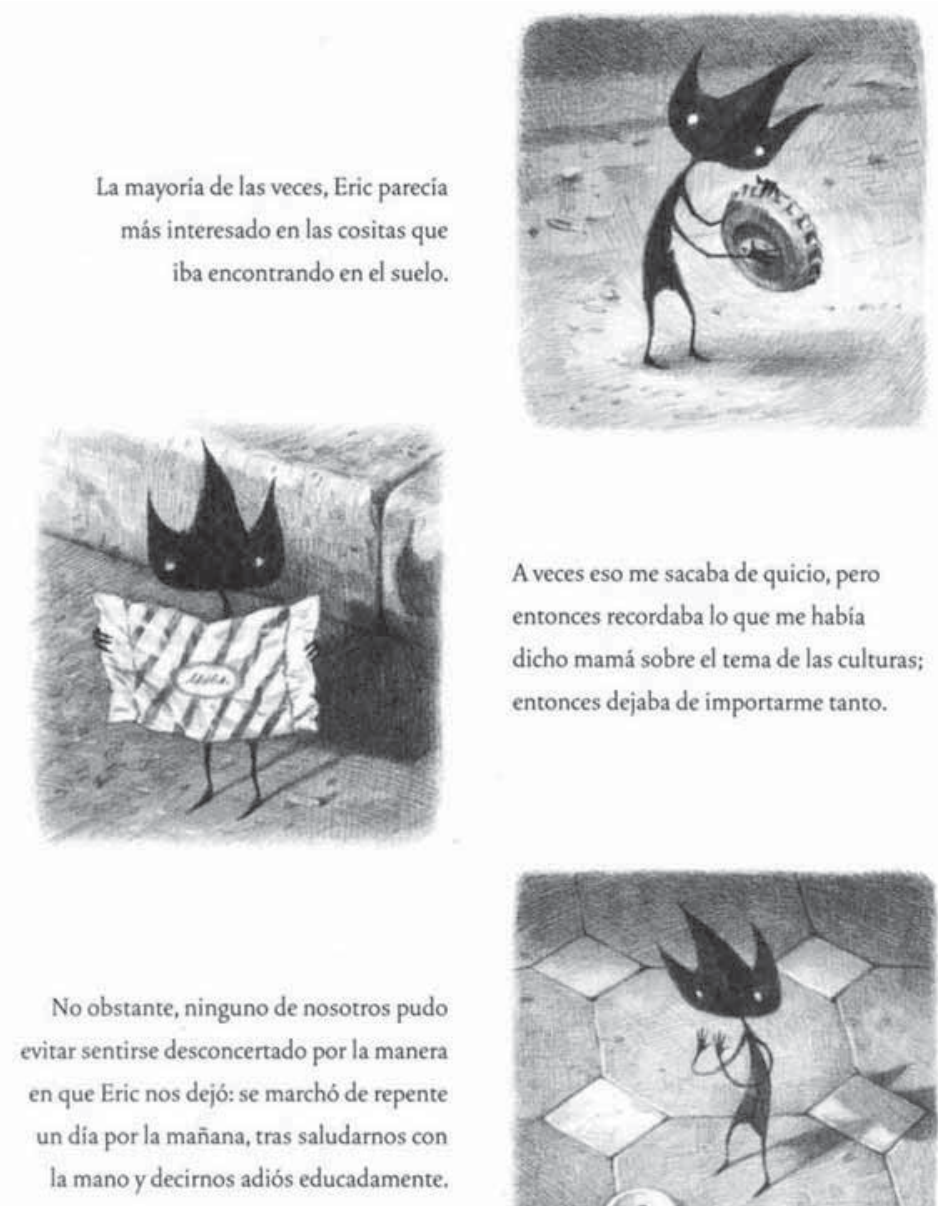

A veces eso me sacaba de quicio, pero entonces recordaba lo que me habia dicho mamá sobre el tema de las culturas; entonces dejaba de importarme tanto.

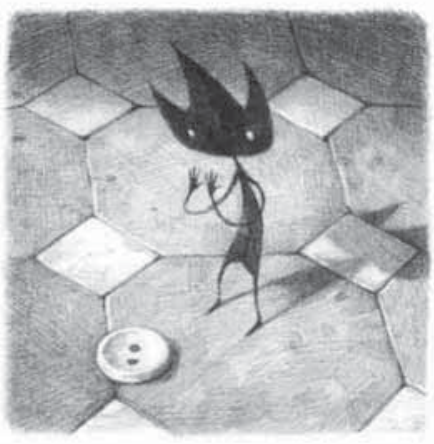

Tan, S. Cuentos de la periferia. Bárbara Fiore Editora. Jerez de la Frontera, España, 2008, p. 14. 
"La mayoría de las veces, Eric parecía más interesado en las cositas que iba encontrando en el suelo. A veces eso me sacaba de quicio, pero entonces recordaba lo que me había dicho mamá sobre el tema de las culturas; entonces dejaba de importarme tanto. No obstante, ninguno de nosotros pudo evitar sentirse desconcertado por la manera en que Eric nos dejó: se marchó de repente un día por la mañana, tras saludarnos con la mano y decirnos adiós educadamente".

En relación con el primer bloque de texto, las imágenes gráficas constituyen una elaboración de tipo ejemplo (muestran el tipo de cosas por las que Eric se interesaba), mientras que los dos siguientes bloques de texto mantienen con estas mismas imágenes una relación de extensión, ya que entregan información adicional, contextual, de lo que sucedió con el personaje.

Pero a pesar del desconcierto provocado por Eric con su partida, el intercambio cultural y el cuestionamiento que este intercambio implica ilumina la experiencia de cada uno y Eric deja un hermoso regalo. Su propia forma de decir adiós y agradecer.

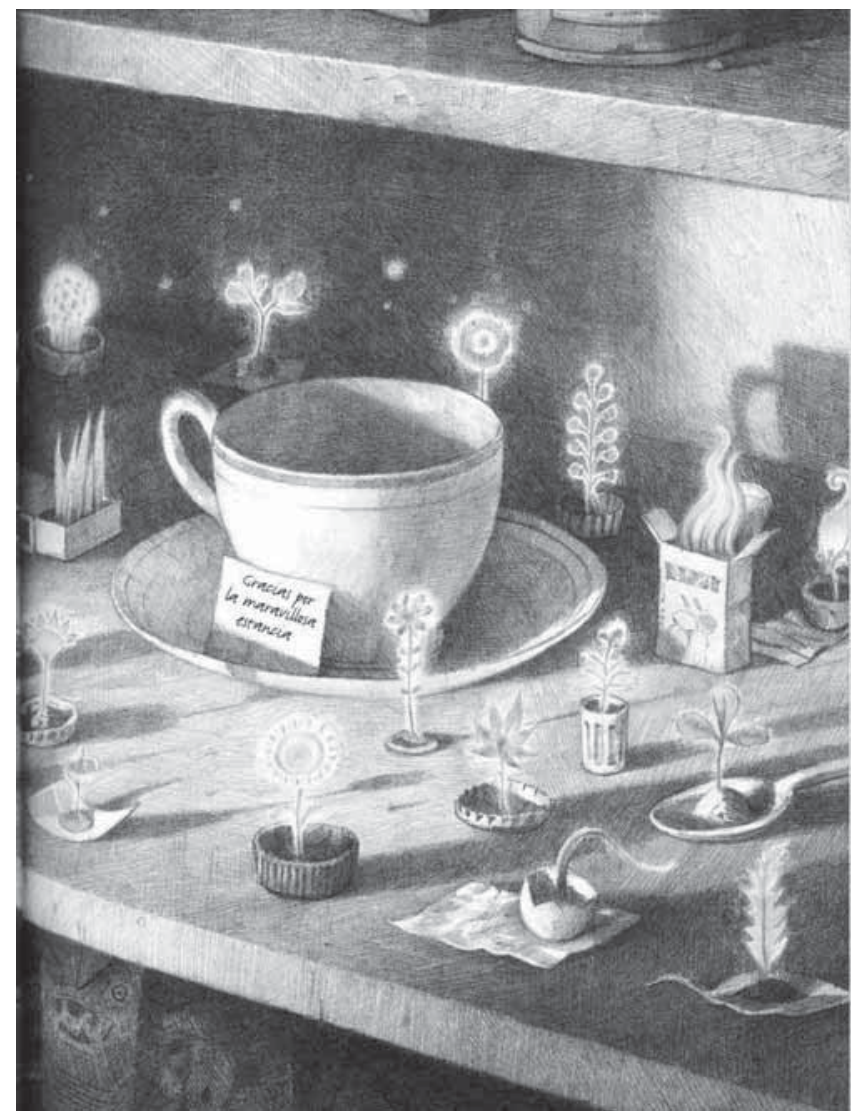

Tan, S. "Cuentos de la periferia". Bárbara Fiore Editora. Jerez de la Frontera, España, 2008. 
Esta tarea de ironizar la realidad, en el sentido de cuestionarnos sobre las bases de nuestro conocimiento y funcionamiento social, también se encuentra en otro hermoso libro de Shaun Tan que se llama La cosa perdida.

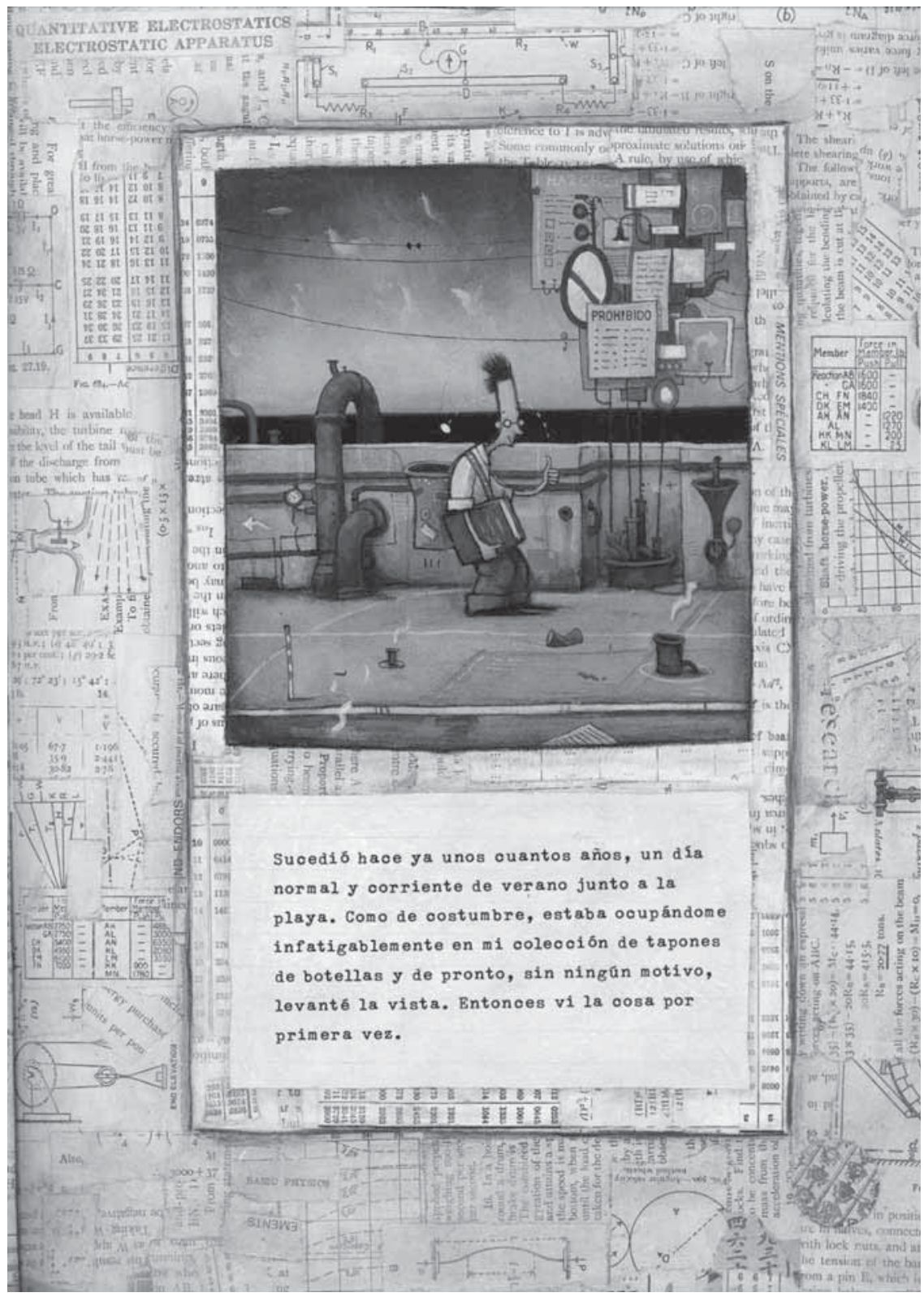

Tan, S. La cosa perdida. Bárbara Fiore Editora. Jerez de la Frontera, España, 2007. 
En esta escena de La cosa perdida el texto cumple la función de expansión del tipo amplificación o realce (es decir, define de manera temporal, espacial o causal la situación presentada en la imagen gráfica). Pero tanto en La cosa perdida como en otras obras de Shaun Tan, el texto no sólo se presenta en lo que podríamos llamar un primer plano de lectura de la imagen, como la voz del autor, la narración propiamente tal: "Sucedió hace ya unos cuantos años, un día normal y corriente de verano junto a la playa. Como de costumbre, estaba ocupándome infatigablemente de mi colección de tapones de botellas y de pronto, sin ningún motivo, levanté la vista. Entonces vi la cosa por primera vez".

Ciertamente, podríamos decir que este texto sitúa espacial y temporalmente la acción y, por lo tanto, cumple la función de Realce o Ampliación, pero el fenómeno es más complejo. En primer lugar, porque el texto ya está connotado como la representación de un texto, escrito con una máquina de escribir (artefacto en extinción o extinto prácticamente) y porque el texto también se encuentra como marco, como soporte, o escenario sobre el cual se desenvuelve la historia.

Ésta es la base sobre la que se plantea el relato y también la memoria, la cultura desde la cual la interpretamos. Nos recuerda lecturas pasadas, papeles acumulados, reciclados, desechos sobre los cuales se puede contar una nueva historia, distinta de la que conocemos o de la que conocieron nuestros antepasados. Esta superposición de textos es también una superposición de capas temporales, como la acumulación de señales, rótulos e indicaciones (arriba a la derecha), de tuberías y válvulas, que evidencian la saturación de informaciones y engranajes que forman el mundo de esta historia, que es tal vez nuestro propio mundo. 


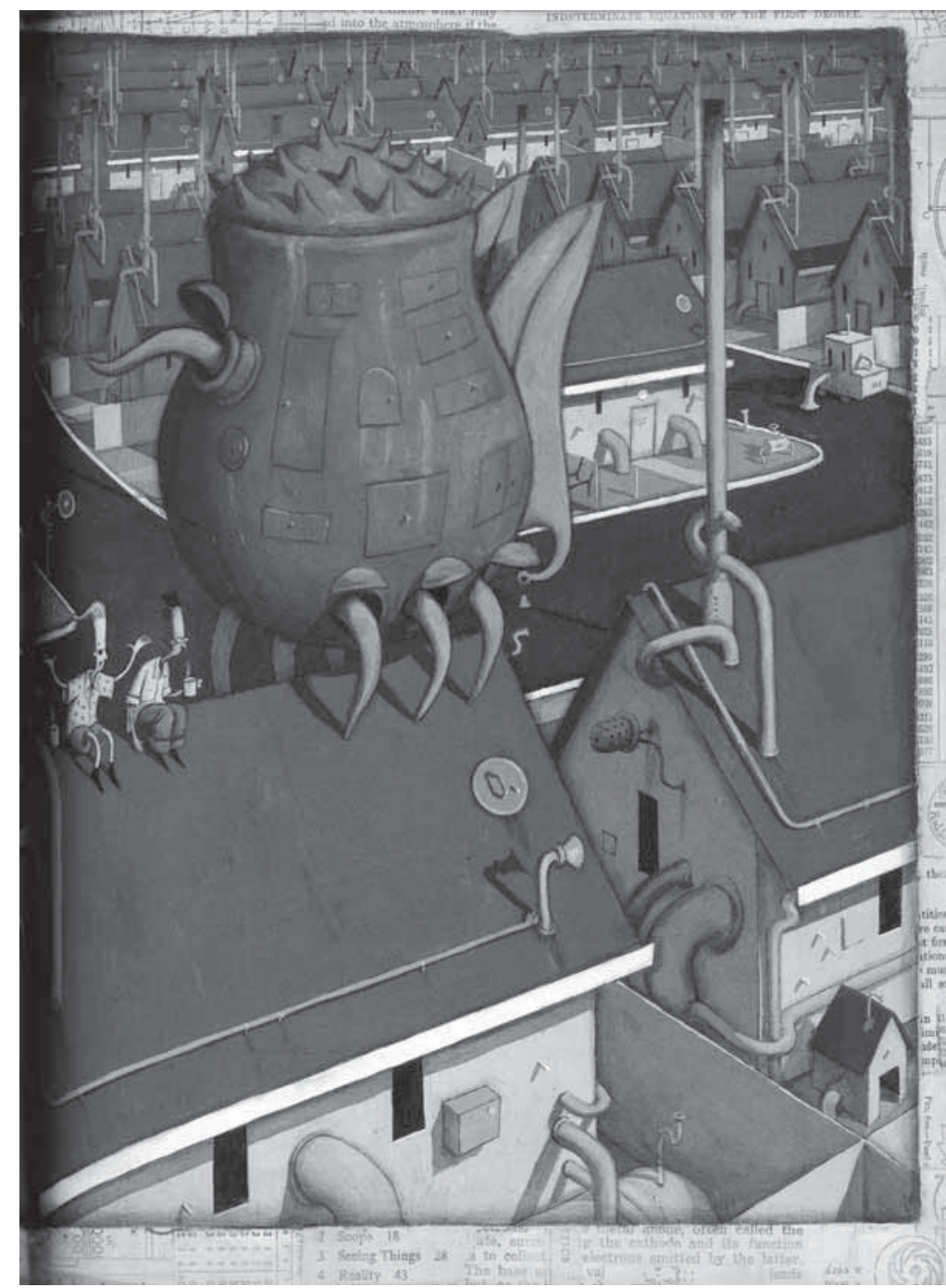

Foucault, M. La arqueología del saber. Siglo Veintiuno. Buenos Aires, 2004.

Pero sobre estos referentes compartidos se plantea una historia que quiebra los planteamientos conocidos. La cosa perdida es un ser y un situación imposible desde nuestra racionalidad. Un comportamiento humano o animal que se plasma en un cuerpo en parte zoomórfico y en parte máquina. Tenazas de cangrejo en un cuerpo blindado y una tristeza de huérfano y abandono. Enorme, además, como para que alguien pudiera extraviarlo. 


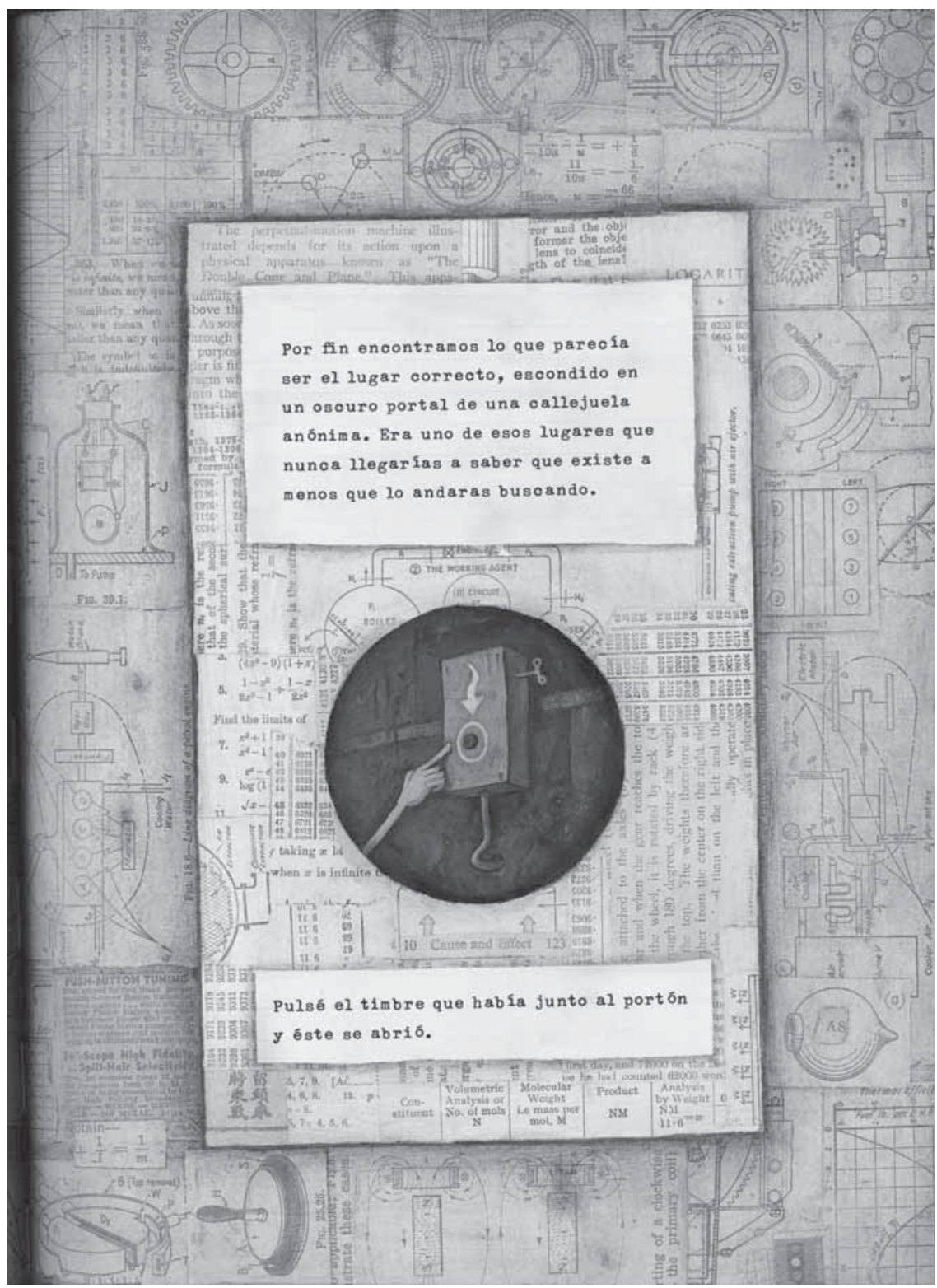

Tan, S. La cosa perdida. Bárbara Fiore Editora. Jerez de la Frontera, España, 2007.

El protagonista de la historia busca un lugar apropiado para dejar la cosa perdida y es así como llega a tocar muchas puertas. En este caso, en el que la imagen elabora el texto, y señala el tipo de timbre, la pared sobre la que su ubica, la mano que lo pulsa, también podemos ver, de acuerdo con la tipología de Martinec y Salway, una serie de relaciones de proyección de tipo "idea" entre texto e imagen como son los 
que se generan en los diagramas, en que se representa, a través de la unión entre texto e imagen, la articulación de ideas y conceptos, y que al mismo tiempo, en este caso, forman una base, un sustrato de resortes, palancas, circuitos, resistencias que constituyen la lógica de nuestro mundo y del que se plantea en la historia.

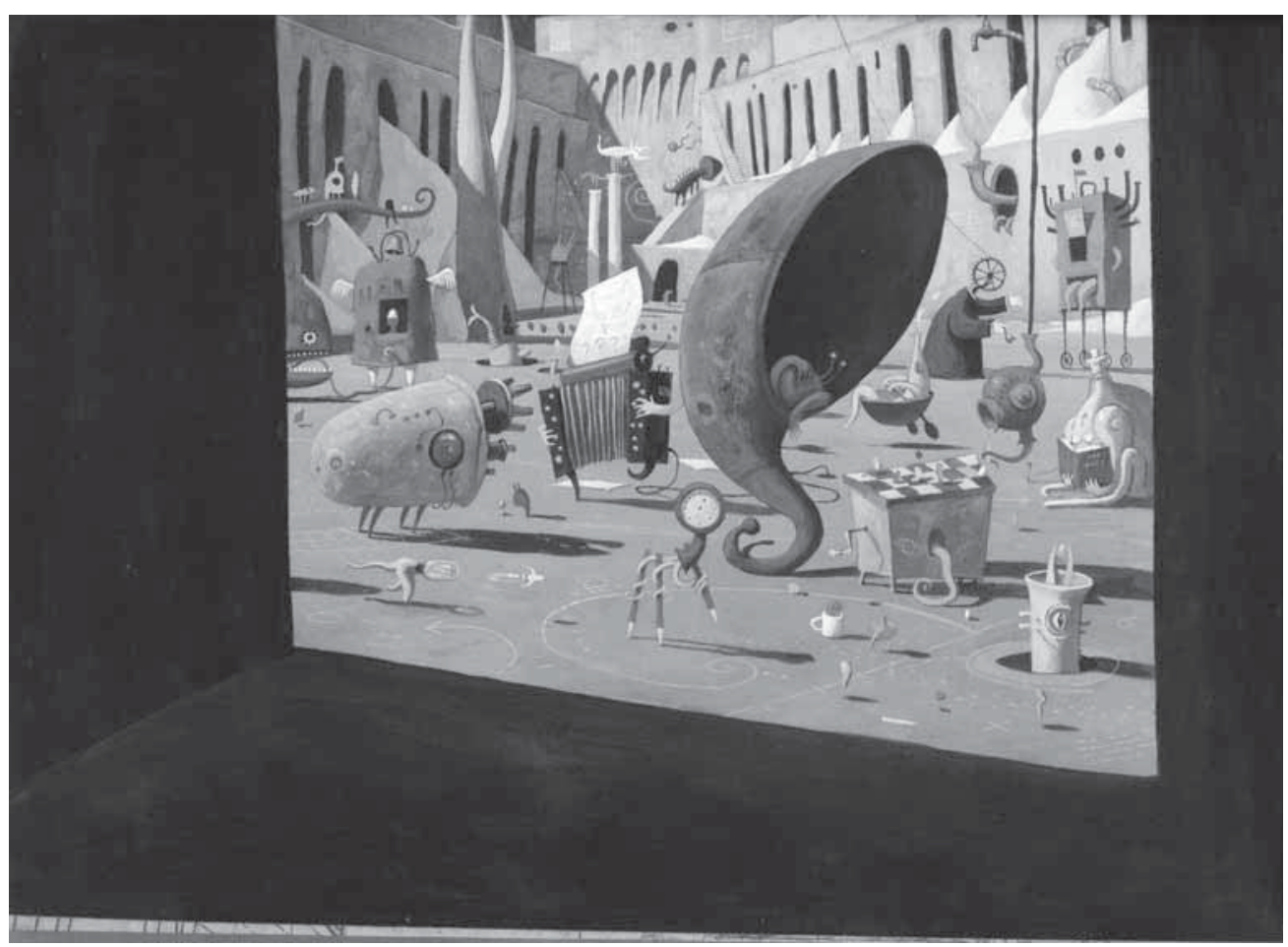

Tan, S. La cosa perdida. Bárbara Fiore Editora. Jerez de la Frontera, España, 2007.

Finalmente, "La cosa perdida" encuentra su lugar entre otra serie de objetos del mismo tipo, en una escena claramente intertextual, que cita la pintura surrealista o metafísica. 


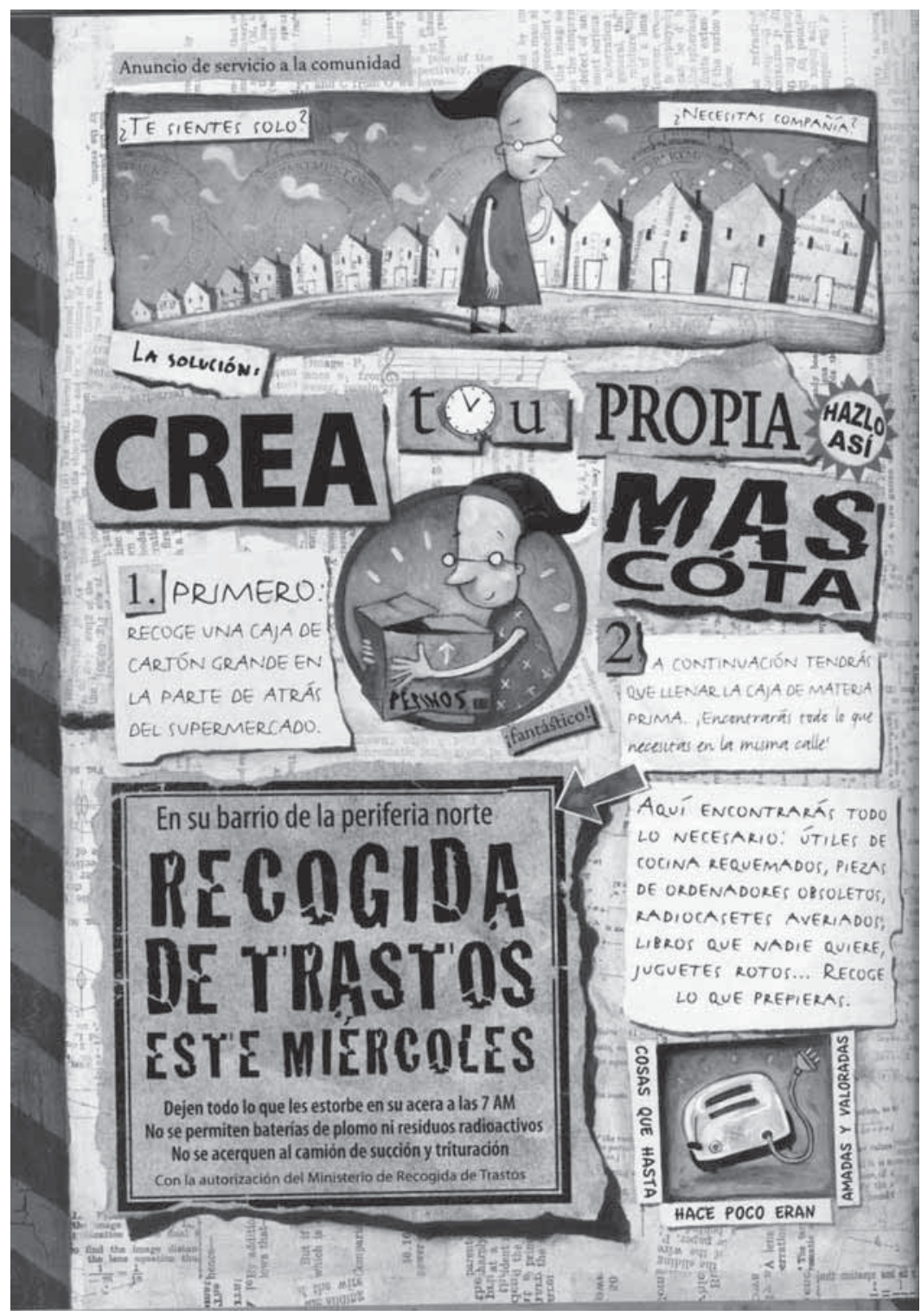

Tan, S. Cuentos de la periferia. Bárbara Fiore Editora. Jerez de la Frontera, España, 2008.

Esta escena de "Crea tu propia mascota", que también forma parte de los Cuentos de la periferia, contiene una serie de relaciones del modelo propuesto por Martinec y Salway. Existen una relación de amplificación o realce en que el texto define al conjunto de la lámina, cuando dice que es un "Anuncio a la Comunidad", también la imagen elabora el texto como en el caso en que el tostador viejo ejemplifica "las cosas que hasta hace poco tiempo eran amadas y valoradas". También hay relaciones 
de extensión, que entregan más detalles sobre los elementos, y de amplificación que detallan tiempo y lugar.

Pero lo que nos interesa aquí principalmente es que refleja uno de los aspectos que quedan relegados en el sistema de clasificación que hemos planteado. Se trata de aquellos casos en que la relación entre texto e imagen tiene su fundamento principalmente en los procesos de interacción, de efectos pragmáticos más que semánticos, lo que la teoría de la estructura retórica planteada por Taboada y Mann (2006) denomina como relaciones de presentación, en las que el efecto que se intenta es aumentar alguna inclinación por parte del lector. El objetivo común de toda publicidad. Son parte de las relaciones de presentación, por ejemplo, la preparación, la motivación, la capacitación. “ ¿Te sientes solo? ¿Necesitas compañía? Crea tu propia mascota. Hazlo así". Este tipo de relaciones de presentación también deberían ser abordadas por el modelo.

Igualmente, es fundamental confrontar estas metodologías con la reacción de los lectores "reales", es decir, con niños frente a la lectura del libro álbum, como sucede en el trabajo de Evelyn Arizpe (Arizpe, 2005) desarrollado en Inglaterra: "Al encontrarse con libros que confundían sus expectativas sobre un texto lineal, la primera reacción de la mayoría de los chicos -dice Arizpe- era observar con más cuidado y hacer un inventario de las cosas "extrañas" que encontraban en las imágenes. Les resultaba más difícil explicar qué significaban, por qué las había incluido el artista. Al principio los niños estaban intentando entender estas incoherencias de manera literal en vez de dar un paso atrás y observar cómo funcionaban dentro de la estructura total del cuento".

Lara (de 10 años) dice: "Lo escrito no explica todo lo que piensas... sólo explica de lo que se trata el libro y lo que está sucediendo, pero no explica lo que sientes y lo que ellos sienten. Así es que me gustan los dibujos más porque puedes pensar más cosas".

Las relaciones de la imagen gráfica, del diseño, con el texto, son un factor muy importante para incentivar la lectura y el libro álbum es un soporte del que la teoría de la comunicación puede extraer conocimientos significativos, por lo que constituye un campo de gran interés para futuras investigaciones que extiendan y profundicen las perspectivas planteadas en este artículo.

\section{Bibliografía}

Arizpe, E. "El juego de los espacios: los lectores y la interacción entre imagen y palabra en el libro ilustrado infantil". AlterTexto lterTexto, Vol. 3 ( $\mathrm{N}^{\circ}$ 6), 2005.

Foucault, M. La arqueología del saber. Siglo Veintiuno. Buenos Aires, 2004.

Guadarrama, L. "La narrativa infantil y juvenil en las modalidades neosubversivas de la posmodernidad posmodernidad". AlterTexto lterTexto Vol. 3 (No 5), 2005. 
Istvanch. ¿Has visto? Ediciones del Eclipse. Buenos Aires, 2006.

Martinec, R. y Salway, A. "A system for image-text relations in new (and old) media". Visual Communication. Vol. 4 (No. 3), 2005, pp. 337 - 371.

Mitchell, W. J. T. "What Is an Image?" New Literary History, Vol. 15 (No. 3), Spring, 1984, pp. $503-537$.

Potter, J. La representación de la realidad. Paidós. Barcelona, 1998.

Saussure, F. Curso de lingüística general. Losada. Buenos Aires, 1988.

Taboada, M. y Mann, W. “Rhetorical Structure Theory: Looking back and moving ahead". Discourse Studies. Vol. 8 (3), 2006, pp. 423 - 459.

Tan, S. Cuentos de la periferia. Bárbara Fiore Editora. Jerez de la Frontera, España, 2008.

Tan, S. El árbol rojo. Bárbara Fiore Editora. Jerez de la Frontera, España, 2006.

Tan, S. Emigrantes. Bárbara Fiore Editora. Arcos de la Frontera, España, 2007.

Tan, S. La cosa perdida. Bárbara Fiore Editora. Jerez de la Frontera, España, 2007. 